\title{
Synthesis and Optimization of Acrylic-N-Acryloxysuccinimide Copolymer Microspheres
}

\author{
Alizar Ulianas ${ }^{\#}$, Nurlely ${ }^{*}$, Yulkifli ${ }^{\wedge}$, Lee Yook Heng ${ }^{+\$}$, Tan Ling Ling $\$$ \\ ${ }^{\#}$ Department of chemistry, Faculty of Mathematics and Science, Universitas Negeri Padang, Sumatera Barat, Indonesia \\ E-mail: alizar_chem@yahoo.co.id \\ *Department of Physic, Faculty of Mathematics and Science, Universitas Indonesia, Jakarta, Indonesia \\ E-mail: kusuma_lely@yahoo.com \\ ^Department of Physic, Faculty of Mathematics and Science, Universitas Negeri Padang, Sumatera Barat, Indonesia \\ E-mail: yulkifliamir@yahoo.com \\ +School of Chemical Sciences and Food Technology, Faculty of Science and Technology, Universiti Kebangsaan Malaysia, 43600 UKM \\ Bangi, Selangor D.E., Malaysia. \\ E-mail: yhl1000@ukm.edu.my
}

\$Southeast Asia Disaster Prevention Research Initiative (SEADPRI-UKM), Institute for Environment and Development (LESTARI), Universiti Kebangsaan Malaysia, 43600 UKM Bangi, Selangor, Malaysia.

E-mail: lingling@ukm.edu.my

\begin{abstract}
A micro-sized poly( $n$-butyl acrylate-co- $N$-acryloxysuccinimide) [poly(nBA-co-NAS] copolymer bio-carrier matrix has been synthesized from n-butyl acrylate (nBA) and $N$-acryloxysuccinimide (NAS) monomers through a single step emulsion photopolymerization protocol. Narrower size distribution of the copolymer microspheres having a size in the range of $0.31-1.04 \mu \mathrm{m}$ was obtained using nBA-SDS composition ratio of $0.25: 5.00(\mathrm{~mL}: \mathrm{mg})$. The FTIR analysis result confirmed the presence of the useful succinimide functional groups on the poly(nBA-co-NAS), which rendered the copolymer microspheres a feasible alternative to other polymers for use as biological immobilization carrier for enzymes and DNA molecules in the fabrication of advanced biosensor devices. The low glass transition temperature $\left(T_{g}\right)$ of the as-synthesized copolymer microspheres signifies the soft and good adhesion properties of the matrix to be attached to the solid support to form the miniature solid-state biosensing devices.
\end{abstract}

Keywords - microspheres; copolymer; immobilization matrix; photo-polymerization

\section{INTRODUCTION}

Emulsion polymerization method has been widely used to synthesize various types of polymeric microspheres. It is usually employed for polymerization process involving hydrophobic monomer, which is insoluble or sparingly soluble in water. Generally, there are four main components for emulsion polymerization reaction to take place [1]. The first component is the monomers, which are slightly soluble or insoluble in the solvent phase. The second component is the initiation material, which can dissolve in the monomer but does not dissolve in the solvent phase. The third component is the surfactant moiety having both hydrophilic and hydrophobic portions as a stabilizer. The fourth component is the solvent such as water.

Several factors may affect the size of the sphere diameter such as the polarity of the emulsion polymerization medium, the amounts of initiator or the monomer used [2] and the stability of the emulsion droplets formed. The stability of the polymer emulsions can be maintained by adding surfactant stabilizer into the emulsion polymerization formulation. The surfactant is necessary to create the micelles for microbeads formation by trapping between the surface of the emulsion droplet and the solvent in order to lower the interfacial tensions and provide stability through electrostatic and steric hindrance mechanisms over the emulsion droplets in the solution, thus prevents agglomeration of the emulsion droplets [3]-[5]

Photo-polymerization method offers a fast and easy way of polymerization because of the single step polymerization process involved. The fundamental principle of photopolymerization is based on the absorption of UV light by the monomer that results in the generation of a few types of active monomers such as free radicals, cations, and anions. Free radicals of the monomer are then joined together by 
chemical bonds to form a polymer chain [6]-[8]. A UV sensitive initiator material such as 2,2-dimethoxy-2phenylacetophenone (DMPP) [9]-[11] is usually required to be added to the monomer to initiate the photopolymerization reaction. The photo-initiator will form free radicals upon irradiated with UV light and subsequently reacts with the monomers to form free radicals in the monomer. Consequently, a polymer is formed as a result of the reaction between free radicals in the monomers.

Polymeric microspheres have been extensively used as biomaterials ranging from the medical application in tissue engineering to analytical biosensor applications owing to the nature of the microspheres, which are physically stable, cellular biocompatibility and enable in vivo detection with sorption methods or binding to the ligand on the particles surface [12]. Biosensors constructed based on the polymer microspheres immobilization matrix for biological molecules, e.g. enzyme, cell, tissue, antibody, and DNA are however possessing certain drawbacks such as loss of enzyme activity and leaching out of biological molecules into the solution, hence reduces the capability of biosensing. These limitations could be overcome by incorporating active biochemical functional groups that can be used for binding of the biomolecule functional groups via robust covalent bond during the synthesis of the biochemically functionalized immobilization carrier, and that the activity of the immobilized biological substances should remain unaltered.

Poly(n-butyl acrylate) [poly(nBA)] is commonly synthesized in the form of membrane for the fabrication of various useful biosensors [9], [13]-[15]. The polyacrylate membrane is hydrophobic, does not require plasticizer, photo-curable and possesses low glass transition temperature (Tg), which renders the acrylic membrane to be easily attached to the other solid support materials such as electrodes. In this study, poly(n-butyl acrylate-co-Nacryloxysuccinimide) [poly(nBA-co-NAS] copolymer microspheres were synthesized. As the n-butyl acrylate (nBA) monomer is insoluble in water, it acts as oil droplet and emulsifies with sodium dodecyl sulfate (SDS) surfactant in a continuous phase of water via emulsion polymerization to form the oil-in-water microemulsion. The $\mathrm{N}$ acryloxysuccinimide (NAS) monomer consists of $\mathrm{C}=\mathrm{C}$ functional group, and that making it possible to form a copolymer with nBA monomer by the photo-lithography technique in the presence of photo-initiator (Fig. 1).<smiles>C=CC(=O)OCC</smiles>

nBA monomer

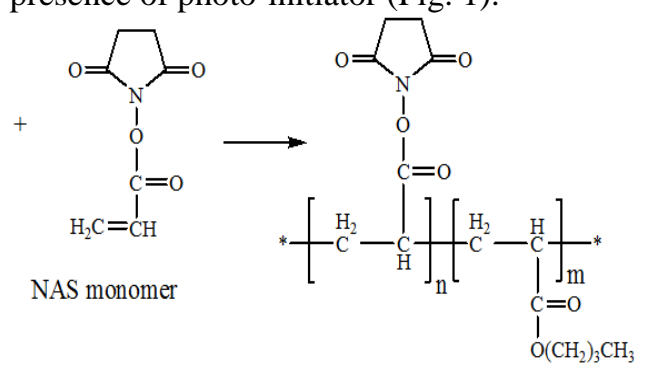

nBA-co-NAS copolymer microsphere

Fig. 1 The proposed chemical reaction between $\mathrm{nBA}$ and NAS to form nBA-co-NAS copolymer microsphere

As the copolymer microspheres comprised of succinimide functional groups, it can be used to react with amine functional group to form amide covalent bond [16], [17]. Thus, the proposed plasticizer-free copolymer microspheres have a potential to be used as a bio-immobilization carrier for immobilization of enzyme and aminated DNA molecules in biosensing applications.

\section{MATERIAL AND METHODS}

\section{A. Chemicals}

Aldrich produced 2,2-dimethoxy-2-phenylacetophenone (DMPP) and 1,6-hexanediol diacrylate (HDDA). Sodium dodecyl sulfate (SDS) and $N$-acryloxysuccinimide (NAS) were obtained from Across and System, respectively. Sigma supplied poly(vinyl alcohol) (PVA) and poly(ethylene glycol) (PEG) (Fig. 2), whilst n-butyl acrylate (nBA) was manufactured by Merck. All the chemical solutions were prepared in deionized water.<smiles>CCC(O)C(C)(C)C</smiles>

(a)<smiles>CC(C)OCCC(C)(C)O</smiles>

(b)

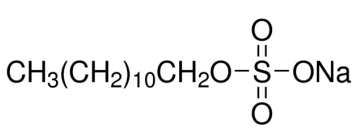

(c)
Fig. 2 Molecular structures of the poly (vinyl alcohol) (a) and poly(ethylene glycol) (b) and sodium dodecyl sulfate (c)

\section{B. Synthesis of Poly(nBA-co-NAS) Copolymer Microspheres}

Poly(nBA-co-NAS) copolymer microspheres were synthesized by microemulsion photo-polymerization method under UV light treatment [18]. The synthesis of NASfunctionalized acrylic microspheres was optimized by varying the amount of $\mathrm{nBA}$ and surfactant in the mixture of $225 \mathrm{~mL}$ HDDA, $50 \mathrm{mg}$ DMPP, $3 \mathrm{mg}$ NAS and $7.5 \mathrm{~mL}$ deionized water using different types of surfactants (PVA, PEG, and SDS) (Table 1).

TABLE I

THE COMPOSITION OF NBA MONOMER AND SURFACTANTS (I.E. PVA, PEG, AND SDS) USED IN THE OPTIMIZATION STUDY

\begin{tabular}{|c|c|c|c|c|}
\hline \multirow{2}{*}{$\begin{array}{c}\text { Microspheres } \\
\text { sample }\end{array}$} & \multirow{2}{*}{$\begin{array}{c}\text { nBA Volume } \\
(\mathbf{m L})\end{array}$} & \multicolumn{3}{|c|}{ Surfactant weight $(\mathbf{m g})$} \\
\cline { 3 - 5 } & & PEG & PVA & SDS \\
\hline A & 0.25 & 5.00 & - & - \\
\hline B & 0.25 & - & 5.00 & - \\
\hline PBSA-1 & 0.25 & - & - & 5.00 \\
\hline PBSA-2 & 1.50 & - & - & 5.00 \\
\hline PBSA-3 & 3.50 & - & - & 5.00 \\
\hline PBSA-4 & 3.50 & - & - & 1.00 \\
\hline PBSA-5 & 3.50 & - & - & 25.00 \\
\hline
\end{tabular}

Oil-in-water emulsification process was carried out by sonicating the mixture in an Elmasonic ultrasonic water bath for $10 \mathrm{~min}$ followed by irradiation with UV light for another 10 min using UV light transmitter unit (RS Ltd.), which consists of four 15-watt light bulbs transmitting UV radiation at the wavelength of $350 \mathrm{~nm}$ under continuous nitrogen gas purging. The as-synthesized copolymer microspheres were finally centrifuged (Hermle) to pellet at $4000 \mathrm{rpm}$ for $30 \mathrm{~min}$, and washed thrice with $0.05 \mathrm{M}$ sodium 
phosphate buffer solution at $\mathrm{pH} 7.0$ followed by air dried at room temperature $\left(25^{\circ} \mathrm{C}\right)$. Substitution of SDS with PVA and PEG surfactants was also carried out to synthesize the copolymer microspheres to examine the influence of different surfactants used on the copolymer microspheres' size.

\section{Physical and Chemical Characterizations of Copolymer Microspheres}

The shape of the resulting poly (nBA-co-NAS) copolymer microspheres depends on scanning electron microscopy (SEM, LEO 1450VP). The microspheres size distribution was determined by Mitutoyo digital diameter measuring tool based on 250 to 325 units of copolymer microspheres image captured by SEM. Perkin Elmer GX FTIR spectrophotometer was used to determine the functional groups of the copolymer microspheres in the wavenumber range of 370-4000 cm-1 using $\mathrm{KBr}$ disc method. The $\mathrm{Tg}$ midpoint value of the copolymer microspheres (3.0-3.5 mg) was characterized by using Mettler Toledo DSC $822 \mathrm{e}$ differential scanning calorimetry (DSC) instrument between the temperature range of $-60{ }^{\circ} \mathrm{C}$ and $0{ }^{\circ} \mathrm{C}$ at the heating rate of $10^{\circ} \mathrm{C} / \mathrm{min}$ under a nitrogen gas flow rate of $40.0 \mathrm{~mL} / \mathrm{min}$.

\section{RESULTS AND DISCUSSION}

\section{Physical and Chemical Characterizations of Copolymer Microspheres}

As Fig. 3 indicates, the type of the surfactant used significantly influenced the diameter size of the assynthesized copolymer microspheres but did not affect the spherical shape of the resulting copolymer microspheres. Smaller particles size with a homogeneous size distribution of the copolymer microspheres was obtained using SDS surfactant $(0.71-7.07 \mu \mathrm{m})$ as compared to the use of PVA $(1.88-19.78 \mu \mathrm{m})$ and PEG $(1.18$ to $9.19 \mu \mathrm{m})$ surfactants (Table 2). This was attributed to the polar head characteristic and a hydrophobic long alkyl chain of the SDS, which gave better stability to the emulsion droplets in water compared to PVA and PEG surfactants with relatively short alkyl chains. Furthermore, the polymer emulsion droplets appeared to last longer with smaller diameter size using SDS surfactant

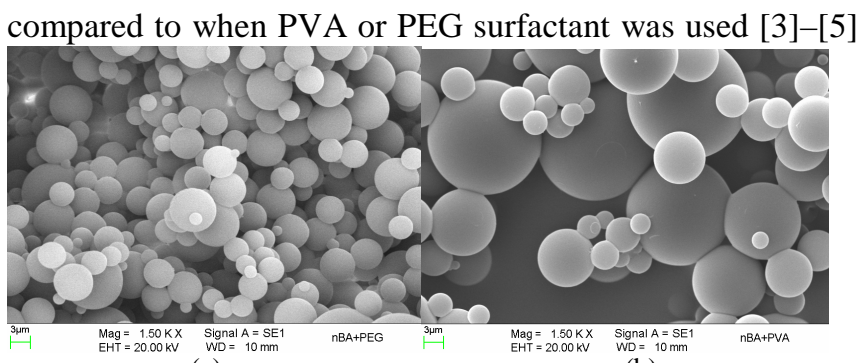

(a)

(b)

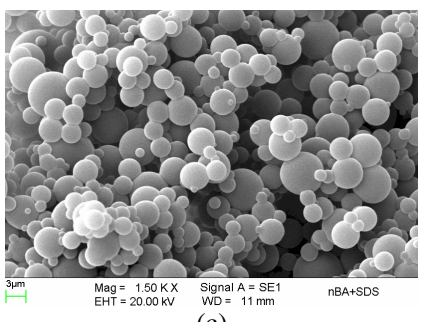

(c)

Fig. 3 Scanning electron micrographs of poly(nBA-co-NAS) copolymer microspheres synthesized using different surfactants i.e. PVA (a), PEG (b) and SDS (c)

TABEL II

EFFECT OF SURFACTANT TYPE ON THE SIZE DISTRIBUTION OF THE ASPREPARED ACRYLIC MICROSPHERES

\begin{tabular}{|c|c|}
\hline Surfactant & Microspheres' diameter range $(\boldsymbol{\mu m})$ \\
\hline PVA & $1.88-19.78$ \\
\hline PEG & $1.18-9.19$ \\
\hline SDS & $0.71-7.07$ \\
\hline
\end{tabular}

\section{E. Effect of Monomer and Surfactant Composition on the Size of the Microspheres}

Various nBA monomer and SDS surfactant compositions were used to synthesize the poly (nBA-co-NAS) copolymer microspheres without changing the surface morphology of the spherical microspheres. However, the size of the microspheres produced can be regulated by varying the composition of $\mathrm{nBA}$ monomer and SDS surfactant in the polymer precursor. Table 3 summarizes the size distributions of the copolymer microspheres with varying $\mathrm{nBA}$ and SDS amounts in the polymer formulation.

TABLE III

EFFECT OF NBA AND SDS COMPOSITIONS ON THE SIZE OF THE COPOLYMER MICROSPHERES

\begin{tabular}{|c|c|c|c|}
\hline $\begin{array}{c}\text { Microspheres } \\
\text { Sample }\end{array}$ & $\begin{array}{c}\text { nBA-SDS } \\
\text { composition }(\mathbf{m L}: \mathbf{m g})\end{array}$ & $\begin{array}{c}\text { Micro-spheres' } \\
\text { diameter range }(\boldsymbol{\mu m})\end{array}$ & $\begin{array}{c}\text { Dominant and smallest } \\
\text { microspheres' diameter }(\boldsymbol{\mu m})\end{array}$ \\
\hline PBSA-1 & $0.25: 5.00$ & $0.31-1.04$ & 0.50 \\
\hline PBSA-2 & $1.50: 5.00$ & $0.32-1.51$ & 0.75 \\
\hline PBSA-3 & $3.50: 5.00$ & $0.68-4.44$ & 2.39 \\
\hline PBSA-4 & $3.50: 1.00$ & $0.87-5.18$ & 4.04 \\
\hline PBSA-5 & $3.50: 25.00$ & $0.52-1.81$ & 1.11 \\
\hline
\end{tabular}

The copolymer microspheres diameter was found to increase proportionally from $0.50 \mu \mathrm{m}$ to $2.39 \mu \mathrm{m}$ with the increasing nBA monomer amount from $0.25 \mathrm{~mL}$ to $3.5 \mathrm{~mL}$ under a solid SDS composition at $5.0 \mathrm{mg}$. This can be explained by the fact that the increasing nBA monomer used has resulted in the increasing size of the polymer emulsion droplets produced in the photopolymerization reaction. However, the use of high nBA monomer amount at $3.5 \mathrm{~mL}$ with low SDS amount between $1.0 \mathrm{mg}$ and $25.0 \mathrm{mg}$ in the emulsion photo-polymerization process exhibited a broad microspheres size distribution (sample PBSA-3, PBSA-4 and PBSA-5), whereby homogeneous copolymer microspheres with uniform size distribution was unachievable. This was because the presence of a large amount of nBA monomers has caused the emulsion droplets to to become unstable in water and easily coalesced to form 
larger emulsion droplets, therefore resulted in a more full microspheres size distribution. The effect of increasing monomer amount on the increasing polymeric microspheres diameter has also been reported [2] [18]The amount of SDS surfactant used to synthesize the copolymer microspheres was further optimized by fixing the nBA monomer loading at $3.5 \mathrm{~mL}$. The copolymer microspheres size was observed to decrease as increasing SDS surfactant amount was added to the oil and water mixture. This was ascribed to the effect of surfactant, which serves to maintain the stability of the emulsion droplets formed by adsorbing at the oil-water interface. The Higher amount of SDS surfactant present in the oil-in-water micro emulsion provided higher stability to the micro emulsion droplets, and that prevented flocculation of micro-sized emulsion droplets into larger droplets [3] [5] [18]. In addition, the emulsion droplets would last longer with a slightly higher SDS stabilizer loading.

\section{F. Chemical Elucidation of Poly(nBA-co-NAS) Copolymer Microspheres}

The functional groups present in the as-synthesized poly (nBA-co-NAS) FTIR determined copolymer microspheres are tabulated in Table 4.

TABLE IV

LIST OF FUNCTIONAL GROUPS PRESENT IN THE ACRYLIC MiCROSPHERES COMPARED WITH THE REFERENCE SPECTRUM OBTAINED FROM FTIR ANALYSIS (SDS WAS USED AS THE SURFACTANT)

\begin{tabular}{|c|c|c|}
\hline \multirow{2}{*}{$\begin{array}{c}\text { Functional } \\
\text { group }\end{array}$} & \multicolumn{2}{|c|}{ Frequency $\mathbf{( c m}^{-1} \mathbf{)}$} \\
\cline { 2 - 3 } & $\begin{array}{c}\text { Acrylic } \\
\text { microspheres }\end{array}$ & Reference [19] \\
\hline $\mathrm{O}-\mathrm{H}$ (strain) & 3450.61 & $3400-3200$ \\
\hline $\mathrm{C}-\mathrm{H}$ (strain) & $2961.13-2874.49$ & $3000-2850$ \\
\hline $\mathrm{C}=\mathrm{O}$ (ester) & 1736.88 & $1750-1730$ \\
\hline $\mathrm{C}=\mathrm{O}$ (amide) & 1698.85 & $1680-1630$ \\
\hline $\mathrm{C}-\mathrm{O}$ (strain) & $1188.99-1066.13$ & $1300-1000$ \\
\hline $\mathrm{CH}_{3}$ (elbow) & $1397.19-1376.24$ & $1450-1375$ \\
\hline$-\mathrm{CH}_{2}$-(elbow) & 1453.53 & 1465 \\
\hline $\mathrm{C}-\mathrm{N}$ (strain) & $1256.42-1165.58$ & $1350-1000$ \\
\hline
\end{tabular}

The FTIR absorption band of the hydroxyl group (-OH) at $3450.61 \mathrm{~cm}-1$ is due to the presence of water molecules as the copolymer microspheres sample was analyzed in wet condition. The adsorption bands of 2961.13-2874.49 cm-1, 1397.19-1376.24 cm-1, and 1188.99-1066.13 cm-1 are corresponding to the respective $\mathrm{C}-\mathrm{H}$ (strain), - $\mathrm{CH} 3$ (bend), $\mathrm{C}-\mathrm{O}$ (strain) functional groups of nBA and NAS monomers. The adsorption band indicates the - $\mathrm{CH} 2$ - functional group (elbow) in the copolymer microspheres at $1453.53 \mathrm{~cm}-1$. The strong and sharp $\mathrm{C}=\mathrm{O}$ functional group absorption bands of nBA and NAS monomers are observed at 1736.88 $\mathrm{cm}-1$ and $1698.85 \mathrm{~cm}-1$, respectively. C-N (strain) functional group from NAS monomer is perceived between $1256.42 \mathrm{~cm}-1$ and $1165.58 \mathrm{~cm}-1$. The presence of succinimide functional group in this copolymer microspheres can thus be used for covalent coupling with biomolecules such as enzymes and aminated DNAs via succinimide-amine coupling reaction [16]-[18] for robust immobilization of biomolecules to the copolymer microspheres carrier matrix. Besides, the monomer composition and surfactant types are not affected to the functional group of polymer and consistent [18].

\section{G. Glass Transition Temperature of the Copolymer Microspheres}

The glass transition temperature $(\mathrm{Tg})$ of the polymer is the temperature at which the polymer changes from a solid (glass) to a rubber state [20]. Tg value may indicate the physical properties of a polymer such as a polymer viscosity [21], [22] For polymer applied in the ion selective membrane, the $\mathrm{Tg}$ value of the polymeric membrane is required to be below the room temperature [9] in order to facilitate the membrane attaches to the substrate support i.e. the electrode. The Tg values of the poly (nBA-co-NAS) copolymer microspheres taken at the midpoint (Fig. 5) of the transition at various nBA-SDS compositions are shown in Table 5 .

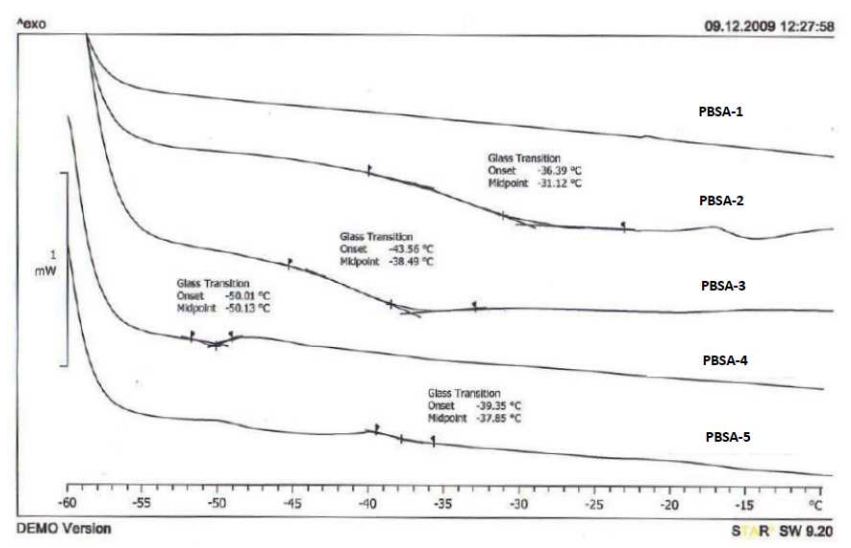

Fig. 5 Glass transition profile of acrylic microspheres

TABLE V

THE TG VAlUeS OF THE POLY(NBA-CO-NAS) COPOLYMER MICROSPHERES PRODUCED WITH VARYING NBA-SDS COMPOSITIONS

\begin{tabular}{|c|c|c|}
\hline $\begin{array}{c}\text { Microspheres } \\
\text { Sample }\end{array}$ & $\begin{array}{c}\text { nBA-SDS } \\
\text { composition } \\
(\mathbf{m L}: \mathbf{~ m g})\end{array}$ & $\begin{array}{c}\mathbf{T}_{\mathbf{g}} \text { midpoint } \\
\text { value }\left({ }^{\mathbf{0}} \mathbf{C}\right)\end{array}$ \\
\hline PBSA-1 & $0.25: 5.00$ & - \\
\hline PBSA-2 & $1.50: 5.00$ & -31.12 \\
\hline PBSA-3 & $3.50: 5.00$ & -38.49 \\
\hline PBSA-4 & $3.50: 1.00$ & -50.13 \\
\hline PBSA-5 & $3.50: 25.00$ & -37.85 \\
\hline
\end{tabular}

The $\mathrm{Tg}$ value of the copolymer microspheres decreased with the increase of the nBA monomer amount, whereas increasing the amount of SDS surfactant, the copolymer microspheres demonstrated increasing $\mathrm{Tg}$ value [2]. The low $\mathrm{Tg}$ value of the copolymer microspheres indicates high elasticity properties of the matrix [9], [13], [15], which could serve as a good candidate carrier matrix to be attached to any plastic support materials.

\section{CONCLUSIONS}

Copolymer microspheres based bio immobilization matrices has been successfully synthesized from nBA and NAS monomers via micro emulsion photo-polymerization. The type of surfactant and the amount of monomer or surfactant used appeared to influence the size as well as the 
$T_{g}$ value of the copolymer microspheres. The low $T_{g}$ value of the copolymer microspheres allows strong adherence of the matrix to any substrate supports. Moreover, the available succinimide ester functional group on the copolymer microspheres further allows covalent immobilization of biological molecules to the matrix surface for the development of versatile biosensors.

\section{ACKNOWLEDGMENT}

We would like to thank the Universitas Negeri Padang for a top-down research grand for support via research funds 1794/UN35.2/PG/2017.

\section{REFERENCES}

[1] G. Odian, Principles of polymerization. John Wiley \& Sons, 2004.

[2] A. M. Usmani and N. Akmal, Diagnostic biosensor polymers. ACS Publications, 1994

[3] K. Landfester, F. J. Schork, and V. A. Kusuma, "Particle size distribution in mini-emulsion polymerization," Comptes Rendus Chim., vol. 6, no. 11-12, pp. 1337-1342, 2003.

[4] A. M. I. Ali, K. Tauer, and M. Sedlak, "Comparing emulsion polymerization of methacrylate-monomers with different hydrophilicity," Polymer (Guildf)., vol. 46, no. 4, pp. 1017-1023, 2005.

[5] X. Liu, Y. Guan, H. Liu, Z. Ma, Y. Yang, and X. Wu, "Preparation and characterization of magnetic polymer nanospheres with high protein binding capacity," J. Magn. Magn. Mater., vol. 293, no. 1, pp. 111-118, 2005.

[6] N. S. Allen and J. F. McKellar, "Photochemistry of man-made polymers," Applied Science, London. p. 216, 1979.

[7] N. S. Allen and J. F. Rabek, New trends in the photochemistry of polymers. Elsevier Applied Science Publishers. Sole distributor in the USA and Canada, Elsevier Science Pub. Co., 1985.

[8] J. P. Fouassier, X. Allonas, and D. Burget, "Photopolymerization reactions under visible lights: principle, mechanisms and examples of applications," Prog. Org. coatings, vol. 47, no. 1, pp. 16-36, 2003.

[9] L. Y. Heng and E. A. H. Hall, "Assessing a photocured selfplasticised acrylic membrane recipe for $\mathrm{Na}+$ and $\mathrm{K}+$ ion selective electrodes," Anal. Chim. Acta, vol. 443, no. 1, pp. 25-40, 2001.

[10] K. S. Mei, L. Y. Heng, and M. Ahmad, "Pemegunan enzim urease dalam bahan hidrogel metakrilat untuk menghasilkan membran biosensor urea," J. Teknol., vol. 45, pp. 53-66, 2006.

[11] Y. P. Ling and L. Y. Heng, "A potentiometric formaldehyde biosensor based on immobilization of alcohol oxidase on acryloxysuccinimide-modified acrylic microspheres," Sensors, vol. 10, no. 11, pp. 9963-9981, 2010.

[12] R. Löbenberg, L. Araujo, and J. Kreuter, "Body distribution of azidothymidine bound to nanoparticles after oral administration," Eur. J. Pharm. Biopharm., vol. 44, no. 2, pp. 127-132, 1997.

[13] L. Y. Heng and E. A. H. Hall, "Methacrylic-acrylic polymers in ionselective membranes: achieving the right polymer recipe," Anal. Chim. Acta, vol. 403, no. 1-2, pp. 77-89, 2000.

[14] L. Y. Heng, S. Alva, and M. Ahmad, "Ammonium ion sensor based on photocured and self-plasticising acrylic films for the analysis of sewage," Sensors Actuators B Chem., vol. 98, no. 2-3, pp. 160-165, 2004.

[15] H. Yu, J. Peng, M. Zhai, J. Li, G. Wei, and J. Qiao, "Synthesis and characterization of poly (n-butyl acrylate)-poly (methyl methacrylate) latex interpenetrating polymer networks by radiation-induced seeded emulsion polymerization," Radiat. Phys. Chem., vol. 76, no. 11-12, pp. 1746-1750, 2007.

[16] J.-P. Chen and S.-H. Chiu, "A poly (N-isopropylacrylamide-co-Nacryloxysuccinimide-co-2-hydroxyethyl methacrylate) composite hydrogel membrane for urease immobilization to enhance urea hydrolysis rate by temperature swing $\boldsymbol{\gamma}^{2}$," Enzyme Microb. Technol., vol. 26, no. 5-6, pp. 359-367, 2000.

[17] C. Chaix, E. Pacard, A. Elaïssari, J.-F. Hilaire, and C. Pichot, "Surface functionalization of oil-in-water nanoemulsion with a reactive copolymer: Colloidal characterization and peptide immobilization," Colloids Surfaces B Biointerfaces, vol. 29, no. 1, pp. 39-52, 2003.

[18] A. Ulianas, L. Y. Heng, and M. Ahmad, "A biosensor for urea from succinimide-modified acrylic microspheres based on reflectance transduction," Sensors, vol. 11, no. 9, pp. 8323-8338, 2011.

[19] D. L. Pavia, G. M. Lampman, G. S. Kriz, and J. A. Vyvyan, Introduction to spectroscopy. Cengage Learning, 2008.

[20] R. E. Kesting, Synthetic polymeric membranes: a structural perspective, vol. 348. Wiley NY etc., 1985.

[21] M. Babazadeh, "Thermal stability and high glass transition temperature of 4-chloromethyl styrene polymers bearing carbazolyl moieties," Polym. Degrad. Stab., vol. 91, no. 12, pp. 3245-3251, 2006.

[22] K. D. Safa and M. Babazadeh, "Glass transition temperature modification of acrylic and dienic type copolymers of 4-chloromethyl styrene with incorporation of (Me3Si) 3C-groups," Eur. Polym. J., vol. 40, no. 8, pp. 1659-1669, 2004. 